\title{
ДИФФЕРЕНЦИАЛЬНАЯ ДИАГНОСТИКА СТЕРОИДНОГО ДИАБЕТА И САХАРНОГО ДИАБЕТА 2 ТИПА У ПАЦИЕНТКИ, ПОЛУЧАЮЩЕЙ ГЛЮКОКОРТИКОИДЫ
}

\author{
А.В. Попович, А.В. Витебская \\ Клинический институт детского здоровья им. И.М. Филатова, г. Москва, ФГАОУВО «Первый \\ МГМУ им. И.М. Сеченова», г. Москва
}

Назначение пероральных препаратов глюкокортикоидов (ГК) является методом выбора при лечении системных заболеваний соединительной ткани. Длительный прием ГК в больших дозах может приводить к формированию медикаментозного синдрома Иценко-Кушинга (МСИК), а в некоторых случаях - к развитию стероидного сахарного диабета (СД). Снижение дозы ГК должно приводить к исчезновению симптомов МСИК, нормализации массы тела и показателей гликемии. При отсутствии тенденции к нормализации показателей, несмотря на снижение дозы ГК, необходимо выявлять другие причины ожирения и его осложнений.

ЦЕЛЬ - демонстрация клинического случая нормализации показателей углеводного обмена на фоне снижения массы тела у пациентки, продолжающей принимать глюкокортикоиды.

Описание клинического случая. В 8 лет у пациентки была выявлена системная склеродермия с поражением кожи, подкожно-жировой клетчатки, желудочно-кишечного тракта, легких, в связи с чем была назначена терапия ГК в дозе, достигавшей 1 мг/кг преднизолона. На фоне терапии ГК отмечен выраженный набор массы тела, повышенный аппетит, диагностирован МСИК.

В 10 лет выявлена артериальная гипертензия, расцененная как осложнение МСИК, назначена гипотензивная терапия, продолжается по настоящее время.

В 13 лет выявлен компрессионный перелом позвоночника на фоне остеопороза, получала бисфосфонаты, в настоящее время продолжает принимать альфакальцидол.

С 13 лет доза ГК снижена до поддерживающей - 5-7,5 мг/сут преднизолона. Несмотря на снижение дозы ГК, все попытки соблюдения диеты в домашних условиях - без эффекта. При нахождении в стационарных условиях - всегда снижение массы тела.

В 17,5 лет при обследовании в детском эндокринологическом отделении рост $161 \mathrm{~cm}$ (SDS -0,20), вес 80,0 кг (ИМТ 30,86 кг/м², SDSимт +2,5), подкожно-жировая клетчатка развита избыточно, распределена равномерно (перераспределение по кушингоидному типу отсутствует). Выявлен СД (гликемия натощак 3,6 ммоль/л, через 2 ч после приема 75 г глюкозы - 13,0 ммоль/л), дислипидемия (общий холестерин 5,3 ммоль//л, ЛПНП 3,5 ммоль/л), неалкогольная жировая болезнь печени, стеатогепатит (АЛТ 66 Ед/л, АСТ 38 Ед/л). К терапии были добавлены метформин (1700 мг/сут) и препараты урсодезоксихолевой кислоты, рекомендовано соблюдение диеты с ограничением легкоусвояемых углеводов и продуктов повышенной калорийности.

На момент обследования проводилась дифференциальная диагностика между МСИК, осложненным ожирением и стероидным СД (диагностированы на фоне приема ГК), и конституционально-экзогенным ожирением, осложненным СД 2 типа (сохраняющееся ожирение на фоне снижения дозы ГК, отсутствие кушингоидного перераспределения подкожно-жировой клетчатки, эффективное снижение массы тела в условиях стационара).

За следующие 4 мес, несмотря на неизменную дозу ГК (преднизолон 5 мг), отмечено снижение массы тела в амбулаторных условиях на 18,7 кг (23\%), в связи с чем прием метформина был отменен. При обследовании в 17,9 лет рост 161 см (SDS - 0,09), вес 61,3 кг (ИМТ 23,00 кг/м², SDSимт +0,66). Отмечена нормализация показателей гликемии (натощак 3,6 ммоль/л, через 2 ч после приема 75 г глюкозы - 6,7 ммоль/л), липидов (общий холестерин 4,5 ммоль//л, ЛПНП 3,0 ммоль/л), трансаминаз (АЛТ 13 Ед/л, АСТ 13 Ед/л).

Выраженное снижение массы тела и нормализация показателей гликемии позволяют говорить об отсутствии МСИК и стероидного СД у пациентки, принимающей ГК в поддерживающей дозе.

ЗАКЛЮЧЕНИЕ. Отсутствие снижения ИМТ у ребенка с ожирением на фоне снижения доз ГК требует проведения дифференциальной диагностики ожирения вследствие приема ГК и конституционально-экзогенного ожирения. Детям с ожирением на фоне приема ГК необходимо проведение скрининга осложнений ожирения, назначение диетотерапии и лечение выявленных коморбидных состояний. 